\section{Visión Electrónica Más que un estado sólido \\ https://doi.org/10.14483/issn.2248-4728}

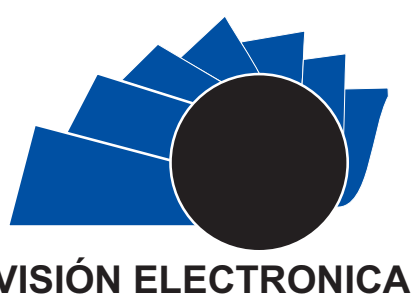

A Case - Study Visión

\title{
Analysis of the spatio-temporal gait parameters of transtibial amputees
}

\author{
Análisis de parámetros espacio temporales de la marcha de amputados transtibiales \\ Yuliana Ruiz-Piragauta ${ }^{1}$, Brigette Paola Torres-Bello ${ }^{2}$, Esperanza Camargo-Casallas ${ }^{3}$
}

\section{INFORMACIÓN DEL ARTICULO}

Historia del articulo

Enviado: 28/11/2018

Recibido: 03/12/2018

Aceptado: 25/12/2018

\section{Keywords:}

Amputation,

Gait,

Software,

Variable temporal space.

\section{Palabras clave:}

Amputación,

Marcha,

Software,

Variable espacio temporal.

\section{ABSTRACT}

In this study we analyzed the spatio-temporal parameters (step length, step time, stride length, stride time, speed and rate) of three unilateral transtibial amputees in order to find the best gait pattern and this verify the adaptation of the prosthesis, using inertial sensors of the TECHNAID $®$ brand in order to make the diagnosis in an objective way; the data were processed using the MARCHA ET software of the DIGITI research group of the Universidad Distrital Francisco José de Caldas. In this study, were analyzed three subjects from the Hospital Militar Central (HMC) the cause of amputation is due to trauma caused by antipersonnel mines. It was found that subjects with unilateral transtibial amputation lean on more time and carry more weight on their healthy lower limb, which leads to an increase in mechanical demand on the knee joint of the amputated leg.

\section{RESUMEN:}

En este estudio se analizaron los parámetros espaciotemporales (longitud del paso, tiempo del paso, longitud de la zancada, tiempo de zancada, velocidad y cadencia) de tres amputados transtibiales unilaterales con el objetivo de buscar el mejor patrón de marcha y así verificar la adaptación de la prótesis, utilizando sensores inerciales de la marca TECHNAID $®$ con el fin de hacer el diagnostico de manera objetiva; los datos fueron procesados utilizando el software MARCHA ET del grupo de investigación DIGITI de la Universidad Distrital. En este estudio se analizaron tres sujetos del Hospital Militar Central (HMC) cuya causa de amputación es por trauma por mina antipersonales. Se encontró que los sujetos con amputación transtibial unilateral apoyan más tiempo y cargan más sobre su extremidad inferior sana, lo que conlleva al aumento de demanda mecánica sobre la articulación de la rodilla de la pierna amputada.

\footnotetext{
Electronics technologist, Universidad Distrital Francisco José de Caldas, Colombia. Current position: Planta purificadora de agua Palma de agua SAS., Colombia. E-mail: yuliana9805@gmail.com. ORCID: https://orcid.org/0000-0002-6892-5275.

Electronics technologist, Universidad Distrital Francisco José de Caldas, Colombia. Current position: Planta purificadora de agua Palma de agua SAS., Colombia. E-mail: brigettetorres98@gmail.com. ORCID: https://orcid.org/0000-0001-7849-2939.

${ }^{3}$ BSc. In Electronic Control and Instrumentation Engineering, Universidad Distrital Francisco José de Caldas, Colombia. Electronic Instrumentation Specialist, Universidad Santo Tomás, Colombia. PhD. In Engineering, Pontificia Universidad Javeriana. Current position: Professor and director of the Research Group DIGITI (Sistemas Digitales Inteligentes) at Universidad Distrital Francisco José de Caldas, Colombia. E-mail: ecamargoc@udistrital.edu.co. ORCID: https://orcid.org/o000-0002-6320-4049.

Cite this article as: Y. Ruiz-Piragauta, B. P. Torres-Bello and E. Camargo-Casallas, "Analysis of the spatio-temporal gait parameters of transtibial amputees", Visión electrónica, algo más que un estado sólido, vol. 1, no. 2, Special edition, july-december 2018. DOI revista: https://doi.org/10.14483/issn.2248-4728
} 


\section{Introduction}

This investigation is based on the study of the spatiotemporal parameters of the human gait, in this the variables of length of the step and of the stride, speed of march, step rate and time of stride of three patients with transtibial amputation with an Amputation period between 0 to 11 years. Each patient has anthropometric characteristics that differ and make the walking cycle unique. That is why the analysis of temporal space variables becomes a fundamental issue to ensure the correct rehabilitation of the patient with an artificial joint.

In Colombia studies about transtibial amputation are very limited despite the amount of amputee population due to antipersonnel mines, this is why this research focused on deepening the issue of walking in patients with transtibial prostheses, using softwares specialized in the capture, sampling and analysis of the temporal variables of the gait to compare it with the references of the authors.

The spatiotemporal analysis of walking is a fundamental tool that facilitates the diagnosis, treatment, monitoring and implementation of rehabilitation methods, among others. This analysis involves some measurements such as gait speed, step length, stride length, step time, stride time and rate [1]. The walking speed is the distance that the body travels forward in the unit of time. The average speed can be calculated as the product of the rate (steps / min) by the length of the stride $(\mathrm{m})$. The rate refers to the number of steps per unit of time and is usually expressed in steps per minute (steps / $\mathrm{min}$ ), in women the average oscillates around 119 steps / min, while in men, this frequency is lower, approximately 113 steps / $\min [2]$.

The most important reason to perform an analysis of the prosthetic gait is to identify and determine the causes that produce the deviations in relation to the normal gait. This procedure requires a detailed knowledge of normal human locomotion, biomechanics, prosthesis adaptation and prosthetic alignment [3]. The adaptation of the transtibial prosthesis (below the knee) depends on each individual and is determined by the dynamic alignment, it is assessed from the walking pattern, considering that it should be a comfortable pattern [4] without deviations and as a result it must not increase the energy use.

The study was carried out in rehabilitation centers where the data was obtained by means of the inertial sensors that the patients carried in the lower extremities, for their respective analysis in the specialized software, it is verified by means of a statistical treatment that the data are valid and in this way show a similarity between the acquired data and the parameters of the bibliography. Having done the previous, begins the study and the comparison between the temporal space variables, anthropometric characteristics and pathologies of each patient.

\section{Materials and methods}

\subsection{Theoreticalbasis}

The purpose of gait analysis is to move the mass of horizontally articulated body segments from one site to another at a constant velocity. The general mechanics is to produce a vertical impulse that counteracts the force of gravity during the phase of double support and simple support, while generating enough muscular force to provide the advancement of the contralateral lower limb and articulate the lower extremities to move the upper body. [5]

\subsection{The step length}

It is defined as the distance between the points of contact of the alternate feet with the ground. The passage time of the left lower limb is the period from the initial contact of the right foot to the initial contact of the left foot. The time of passage of the lower right limb is the time from the initial contact of the left foot to the initial contact of the right foot. [6]

The length of the step is defined by equation (1).

$\mathrm{LP}=$ Speed / (Step rate per minute) $(1)$

LP: Step length $(\mathrm{m})$

\subsection{The rate of steps}

It is the number of strides or steps that a person can take at a certain time when he is walking at spontaneous speed. The length of the stride is the distance in the direction of progression between successive points of support of the same foot on the ground. A stride is composed of two steps, so two step lengths constitute a stride length. The stride time is defined as the time interval in which it takes the same foot to touch the ground in two supports. [6]

The rate of steps can be determined by means of equations (2), (3) and (4)

$\mathrm{CD}=($ Number of steps $) /$ Time $(2)$ 
CD: Step rate (steps / s).

-Step number (steps)

-Time (s)

-Second equation (3) for step rate.

$\cdot \mathrm{CD}=$ Speed / (Stride length * 120) (3)

-Speed (meters / s)

-Stride length (m).

- Third equation for (4) Step rate.

$\cdot \mathrm{CD}=600 /$ (Time to give 10 steps $)(4)$

-CD: Step rate (steps / min)

-Time taken to take 10 steps (s). [6]

\subsection{The length of the cycle or stride}

It refers to the average distance between two consecutive heel collisions of the same foot. According to Perry, this value is $141 \mathrm{~cm}$ for both sexes, $128 \mathrm{~cm}$ for women and $141 \mathrm{~cm}$ for men [7]. In the present study, the parameters to study are the step length, step rate, stride length and stride time.

The length of the stride is stated with the equation (5)

$\mathrm{LZ}=$ Speed $*$ Stride time $(5)$

LZ: Stride length (m).

Speed $\left(\mathrm{m}^{*} \mathrm{~s}-1\right)$.

Stride time (s). [6]

\subsection{The stride time}

It is determined by the equation (6).

$\mathrm{TZ}=120 /($ step rate $)(6)$

TZ: Stride time (s).

rate (steps * min-1). [6]

Next, the estimated values are presented from research carried out by some authors who have studied the spatiotemporal parameters of gait.

\begin{tabular}{|c|c|c|}
\hline PARAMETER & $\begin{array}{c}\text { UNIT OF } \\
\text { MEASURE }\end{array}$ & VALUE \\
\hline Leng of step & meters & $\begin{array}{c}0,77 \pm \\
0,008\end{array}$ \\
\hline Step of rate & Steps/minute & $\begin{array}{c}110,7 \pm \\
6.9\end{array}$ \\
\hline Stride length & meters & $\begin{array}{c}1,55 \pm \\
0,17\end{array}$ \\
\hline Stride time & seconds & $\begin{array}{c}1,10 \pm \\
0,06\end{array}$ \\
\hline
\end{tabular}

Table 1. Spatial data of the march validated by Camera and Van Uden. [9)

\subsection{Capture system.}

In the research several software were used that allowed the acquisition and analysis of the data, these softwares were:

\subsection{TECH-NAID}

The capture system is a device that collects the information of human's biomechanics, the system that was used is called TECH-NAID. It contains inertial sensors which measure acceleration and angular velocity, this system is supported by gyroscopes, accelerometers and magnetometers. The captures are transmitted in real time via USB or Bluetooth at a maximum distance of $50 \mathrm{~m}$ indoors or $150 \mathrm{~m}$ outdoors [8]. About 12 captures were taken for each patient with around 280-310 samples during the walking cycle at a frequency of $50 \mathrm{~Hz}$. It was necessary to associate each inertial sensor according to the location of each limb and to put a reference sensor, in this case was Lumbar, from this sensor the other sensors are configured and located sequentially; both in the software, as in the patient. For the capture of data, the option of Angles / Orientation was selected.

\subsection{TECH-MCS Studio 4}

The TECH-MCS Studio 4 software is the complement of Tech MCS. The different configurations allow to visualize and capture all the movements of the body in real time and visualizing in avatars and $3 \mathrm{D}$ graphics. From this you can export text documents which are compatible with Excel or Matlab. This is fully commercial and downloaded to obtain the data delivered by TECH NAID sensors. The data delivered by the software are shown graphically, in this case focused on the number of samples at each extremity during a certain amount of time and the angular variation in joint movements when the cycle is running

\subsection{MarchaHumana ET.}

The MarchaHumana ET software is in charge of identifying and obtaining the spatiotemporal parameters of the human march by means of the data acquired with the sensors of the TechNaid motion capture equipment. This software allows to obtain data such as step length, stride length, step time, step rate, stride time and gait speed; It was a development of the DIGITI research group of the Universidad Distrital Francisco José de Caldas. Figure 3 shows the values that are acquired for each of the space-time parameters from the MarchaHumana ET software (see Figure 1). 


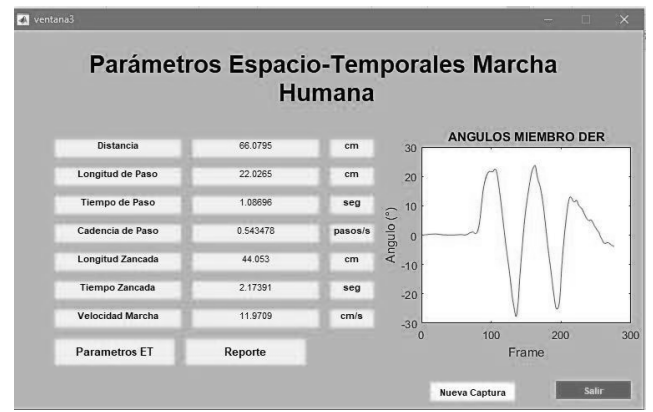

Figure 1. Spatial-temporal parameters window of the MarchaHumana ET Software. Source: own.

\section{Methodology}

The study of spatio-temporal parameters was divided into four stages: Analysis of data to be compared, data acquisition, data processing and analysis of results.

\subsection{Analysis of data to be compared.}

Spatio-temporal parameters indicate values of human gait such as step length, stride time, stride length, gait speed and step time. Which allow to conduct studies to detect anomalies in the gait.

The parameters are acquired from the MarchaHumanaET Software and verified by statistical methods for the analysis

\subsection{Acquisition of data.}

Patients are dressed with the Tech Naid equipment sensors and the appropriate configuration of the TECH-MCS Software; In this way, possible errors are corrected when the data is exported. During the gait the patients walk approximately 7 meters in which the equipment is constantly active and receiving data. CAPA file is exported, this contains the angles of each extremity (left thigh, right thigh, left leg, right leg, right foot and left foot) divided into columns

\subsection{Data processing.}

Of the captures obtained by each one of the patients, which have the spatio-temporal parameters mentioned above, the arithmetic mean is applied to obtain a weighted of the captures. To these results we proceeded to apply the ANOVA Test which relates the variation between the obtained data, by means of the variance of each one it was concluded that the data showed a normality and could be worked satisfactorily.
We proceeded to perform the Tukey test which allowed to calculate the degrees of freedom that had the data of each patient and proceed to conclude if they maintain a relation or not. Stride length, step length and step rate of each patient are processed to reach the conclusion that the data obtained could be analyzed for the study of the spatiotemporal parameters of the amputees.

\subsection{Patients}

The inclusion criterion was: transtibial prosthesis user, functional on the march, without external help, with normal mobility range, prosthetic alignment certified by the prosthetics technician of the HMC, each individual signed the informed consent. All of the individuals have as a cause of amputation trauma from antipersonnel mines and use Ottobock's uniaxial foot.

Patient No. 1: The patient has a height of $169 \mathrm{~cm}$, a mass of $70.6 \mathrm{~kg}$ uses a transtibial prosthesis and his age is 27 years using prosthesis for 7 years.

Patient No 2: This patient has a height of $185 \mathrm{~cm}$, a mass of $75 \mathrm{~kg}$ uses a transtibial prosthesis (empty prosthesis and dynamic foot), with an age of 24 years and use of the prosthesis for 4 months. Figure 3 shows the patient and the type of his prosthesis (this image is published with the consent of the patient).

Patient No 3: The patient measures $170 \mathrm{~cm}$, with a mass of $80 \mathrm{~kg}$ using a transtibial prosthesis (dynamic foot, suspension prosthesis per pin, endoskeleton design), with an age of 42 years and use of the prosthesis of 11 years. In figure 6 the patient No 3 is observed performing the march (this image is published with the consent of the patient). See figure 2.

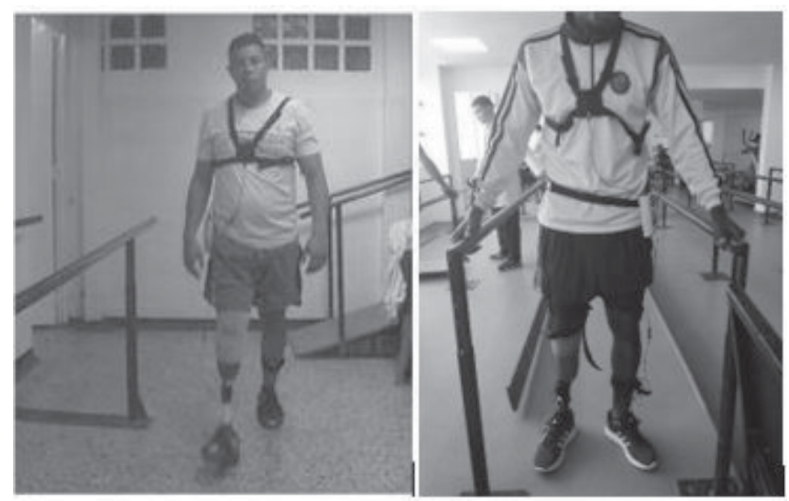

Figure 2. Patient No2 (Left) and Patient No 3 (Right) wearing the TECH NAID sensors (this image is published with patient's consent). Source: own. 


\section{Results and discussion}

\subsection{Statistical validation of the data.}

After performing the ANOVA and Turkey tests on the captures obtained from the MarchaHumanaET software. Table 2 shows a significant variation of the patients in relation to the time-space variables of the general parameter. The data in the table is below the general parameter. The margin of error of the data obtained is presented in the following figures.

\begin{tabular}{|c|c|c|c|}
\hline Spatiotemporal parameter patient & Patient 1 & Patient 2 & Patient 3 \\
\hline Step length (meters) & 0.46232 & 0.4605 & 0.53934 \\
\hline Step rate (steps / min) & 94.7272 & 88.446 & 81.5700 \\
\hline Stride length (meters) & 0.92463 & 0.9209 & 1.07868 \\
\hline Stride time (seconds) & 1.40303 & 1.3556 & 1.50773 \\
\hline Time of passage (seconds) & 0.70151 & 1.74376 & 0.753855 \\
\hline Gait speed (centimeters / seconds) & 71.0223 & 67.602 & 74.126 \\
\hline
\end{tabular}

Table 2. Space-temporary variable data for each patient. Source: own.

\subsection{Acquired values}

Figure 3 shows how there is a margin of error in the length of the step of an amputee with literature, as in the length of stride.
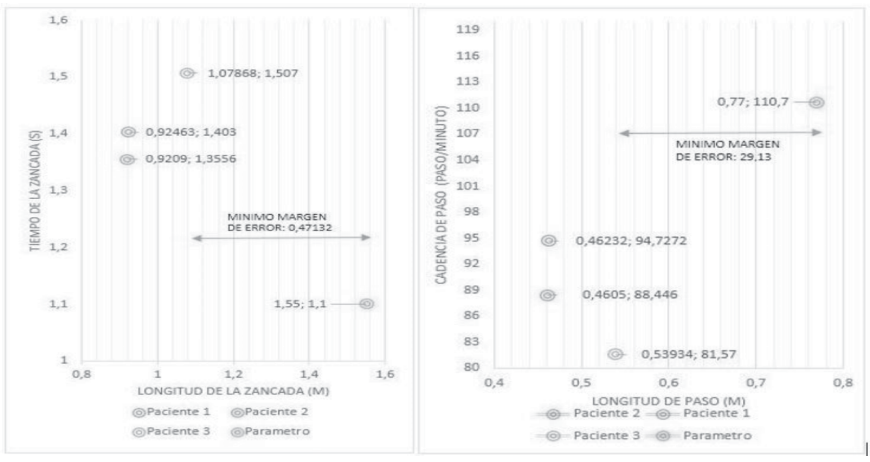

Figure 3. Steps rate Vs Length of the steps of the patients studied and Stride time vs Stride length of the patients studied. Source: own.

Figure 4 shows the response of the lower extremities in the sagittal plane of the patients when the walking cycle is executed, in the present investigation the graphs are emphasized in the moments of Flexion / Extension.
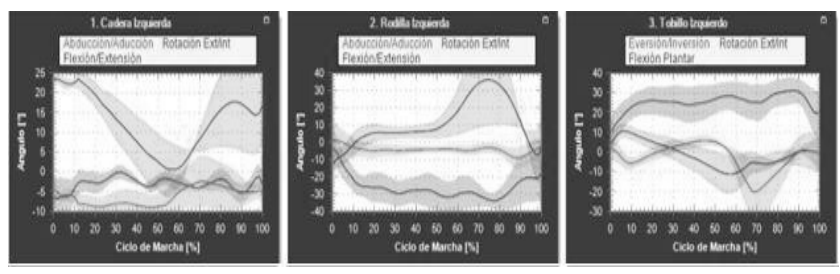

Figure 4. Angle relation Vs Cycle of the gait of the lower extremities of amputees. Source: own.
Figure 5 shows that the TechNaid software captures about 300 samples in a running cycle time. This depends on the patient's reaction and his performance in the gait
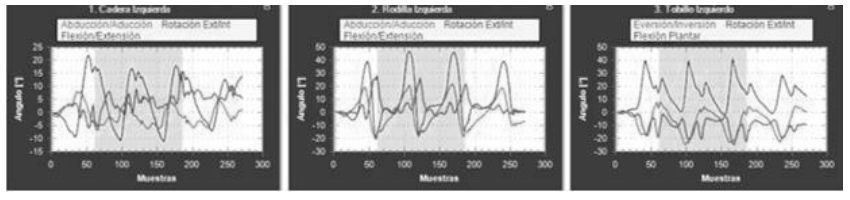

Figure 5. Number of samples in the lower extremity Left of the amputees. Source: own.

In the sagittal plane, the period of the march where the initial contact is made the hip flexion must have an angle greater than $20^{\circ}$ in the amputees this angle is equivalent with a value of $20^{\circ}-30$, the extension of the angle's knee is $0^{\circ}$ and this is equivalent to the data acquired by the software.

At the moment of the discharge of the weight, the flexion of the hip must be greater than $20^{\circ}$. At this moment it is evident how the right side of the hip loses angular value and this side is where the pathology is located, the knee flexion it must have an angle of $15^{\circ}$. In the medium support, the hip flexion must have an angle of $\mathrm{O}^{\circ}$ and the knee must have an angle of $5^{\circ}$, here it is also evident that the side where the pathology has an anomaly since it has a value below saying. When the moment in which the foot takes off from the floor occurs, a hyperextension of the hip happens in average angles of $10^{\circ}-20^{\circ}$ and a knee extension of $0^{\circ}$. At the end of the support phase, when the fingers take off, a hip hyperextension of $10^{\circ}-20^{\circ}$ and a $30^{\circ}$ knee flexion occurs.

In the initial rolling phase, the hip flexion should be $20^{\circ}$ and a knee extension of $60^{\circ}$, in the mean balance the hip flexion is $30^{\circ}$ and a knee extension of $30^{\circ}$ and in the final balance Hip flexion should be $30^{\circ}$ and $\mathrm{o}^{\circ}$ in the knee extension.

\section{Discussion}

The patients show a delayed response at the start of the gait, this causes a recharge force in the first step to the normal limb and thus alter the walking cycle. A quick recovery is evidenced in patient No 2 and in patient No 3 its great trajectory with the prosthesis has similar flexion, rotation and extension movements in its two extremities, it is clarified that this differs in the conditions of the patients, the type of recovery and the type of prosthesis. 
The patient with the empty prosthesis demonstrates greater confidence and security when walking because he reacts faster compared to the other two patients, which means that his stride time is close to that of the general parameter, however, since he has a delayed response to his steps they tend to be shorter so the stride length moves away from the parameter and this is the case with the other patients.

The previous is more evident in the step rate considering that, although patients present joint movements similar to a healthy patient, the pace of the step is modified. Emphasis is placed on the type of prosthesis since observing patients with empty prosthesis and suspension prosthesis per pin is evidence of its adaptability to the environment and its type recovery time. In addition, the dynamic foot design of the patients is limited in joint movements, mainly in abduction and adduction. Important factor for a normal running cycle.

\section{Conclusions}

The patient's reaction at the start of the gait cycle is delayed. This is due to sequelae that produced the amputation as the recovery of movement.

It was found that subjects with unilateral transtibial amputation support more time and carry more weight on their healthy lower limb, which leads to an increase in mechanical demand on the knee joint of the amputated leg.

It was found that the length of the step is smaller in amputees, which coincides with the literature that assumes that this is due to the insecurity of performing the support only in the amputated leg.

It was checked for a correct cycle of the gait that patients have a prosthesis according to their physical conditions, also that constant physical activity ensures that patients can adapt to the prosthesis, having security and reaction to start the gait.

The mistakes of the spatiotemporal variables are: Length of the step in $36.7 \%$, step rate $20.282 \%$, stride length of $37.116 \%$ and stride time of $29.2836 \%$ in relation to the literature. It is confirmed that the spatiotemporal parameters of the human gait get affected by the use of a prosthesis, considering that comparing the values of these parameters in 3 amputated patients vs a general pattern of an author, ranges of difference are found.
The study allows therapists of amputees patients to have control of the medical evolution of patients and also have support to make changes in the prosthesis or in the treatment that each patient is carrying out.

For the companies that design lower limb prostheses, the study is interesting because it can contribute to an in-depth study of the functionalities of the prosthesis since not only is comfort and the possibility of walking action important, but it is also important that the patient's progress presents normal patterns; so the rehabilitation will be totally favourable.

It is important that the study not only be applied to amputees but also to patients who have suffered from lower limb pathologies, corroborating that the treatment was convenient and that the gait obey with the spatiotemporal parameter studied in this investigation.

Statistical methods such as ANOVA and Tukey are fundamental for investigations such as these, since it is allowed for us to verify that the data acquired by software are closely related to the data studied by the referenced authors. It was verified with the ANOVA analysis that the variance between the acquired data was minimal, which allowed to perform the other analysis procedures.

\section{Acknowledgments}

We would like to thank the Universidad Distrital Francisco Jose de Caldas for their support in the studies, the DIGITI research group attached to the University for the valuable follow-up to the study and for allow the use of the implemented equipment. Volunteers are also thanked for allowing the study of their body to carry out this research; finally, to the Hospital Central Militar and the orthopedic and rehabilitation center for providing spaces to acquire the measurements of each of the patients.

\section{References}

[1] L. Luengas, E. Camargo and G. Sanchez, "Modelling and simulation of normal and hemiparetic gait”, Frontiers of Mechanical Engineering, vol. 10, no. 3, 2015, pp. 233-241. http://doi.org/10.1007/s1 1465-015-0343-0

[2] F. Molina- Rueda, "Estrategias de control motor en sujetos protetizados con amputación transtibial unilateral: unilateral análisis instrumental”, thesis PhD., Universidad Rey Juan Carlos, Madrid, España, 2017. 
[3] M. Lenhart, P. Pasquina and R. Cooper, "Care of the combat amputee", Washington DC, USA: Department of the Army, 2010.

[4] M. Leblanc, "Give Hope - Give a Hand", 2011. [Online]. Ava il a ble a t: https://events.stanford.edu/events/263/263 $\underline{95 /}$

[5] I. Tolosa-Guzmán, J. A. Castillo-Martínez, "Introducción al análisis de la marcha", Bogotá: Editorial Universidad del Rosario, 2013.

[6] J. Camara, "Análisis de la marcha: fases y variables espacio-temporales", Entramado, vol. 7, no. 1, 2011 , pp. 160-173.

[7] J. Perry and J. Burnfield, "Gait analysis: normal and pathological function”, J. Sports Sci. Med., vol. 9, no. 2, 1992.

[8] Technaid, "Conexión recomendada de una red de 16 IMUs para el cuerpo humano”, 2016. [O n line ]. Available a t: http://www.technaid.com/wpcontent/uploads/2016/05/Conexio\% $\mathrm{CC} \% 8$ 1n-recomendada-de-una-red-de-16-IMUspara-el-cuerpo-Humano-ES.pdf

[9] C. Van Uden and M. Besser, "Test-retest reliability of temporal and spatial gait characteristics measured with an instrument walkway system (GAITRite)", BMC Musculoskeletal Disorders, vol. 5, no. 13, 2004, pp. 134-141. https://doi.org/10.1186/1471$\underline{2474-5-13}$ 